\title{
Socio-spatial cognition in vervet monkeys
}

Ronald Noë \& Marion Laporte

R. Noë (corresponding author)

Psychologie, Université de Strasbourg

\& DEPE (IPHC-CNRS), Strasbourg France

M. Laporte

Université de Rennes 1

Laboratoire EthoS 'Ethologie Animale et Humaine'

UMR 6552-CNRS., Station Biologique, Paimpont, France

\begin{abstract}
Safety-in-numbers is thought to be the principal advantage of living in groups for many species. The group can only provide protection against predators, however, when group cohesion is maintained. Vocalisations are used to monitor inter-individual distances, especially under conditions of poor visibility, but should be avoided in the presence of predators. Mentally tracking the movements of silent and invisible group members would allow animals foraging in dense vegetation to stay close to their group members while reducing the use of vocal contact. We tested the socio-spatial cognitive abilities of wild vervet monkeys (Chlorocebus pygerythrus) by comparing their reactions to plausible and implausible displacements of group members simulated by sound playbacks. Our methods are comparable to those used in studies of 'object permanence' and 'invisible displacements' of inanimate objects. Our results show that vervets can track the whereabouts of invisibly and silently moving group members, at least over short periods of time.
\end{abstract}

Keywords: spatial cognition; social brain; group cohesion; field experiment; vervet monkey; Chlorocebus pygerythrus 


\section{Introduction}

'The social brain' is shorthand for a now widely accepted explanation of the evolution of advanced cognitive abilities in animals and especially primates. The social brain hypothesis states that group living has selected for complex cognitive capacities, resulting in an increase in brain size, notably the neocortex (Dunbar 1992, 1998, 2003; Humphrey 1976; Whiten and Byrne 1988). This explanation provides an alternative to the idea that advanced abilities evolved in reaction to ecological challenges (CluttonBrock and Harvey 1980; Harvey and Bennett 1983; Sawaguchi 1992). The tendency to seek the company of conspecifics, in turn, is thought to have evolved under predation pressure according to the 'socio-ecological hypothesis' (Sterck et al. 1997; van Schaik 1983; van Schaik and van Hooff 1983). Group-living comes at a cost, however, notably in the form of increased competition for food and mates (Cheney and Seyfarth 1987; Dunbar 1998; van Schaik 1983), but also as an increased risk of contracting infectious diseases (Altizer et al. 2003 and references therein; Nunn et al. 2008). Cognitive challenges specific to group-living animals include keeping track of the interactions with group members, of relationships between third parties, of changes in dominance relationships, forming alliances as well as monitoring alliances formed by others and so forth (Bergman et al. 2003; Cheney and Seyfarth 1990; Dasser 1988; Dunbar and Shultz 2007; Range and Noë 2005; Shultz and Dunbar 2007; Shultz et al. 2011). One cognitive challenge directly related to the 'safety-in-numbers' function of sociality is seldom discussed, however: the necessity to keep track of the spatial positions of group members even under conditions of poor visibility as found in dense forests and scrublands and especially when vocalisations increase the individual predation risk. We propose the label "socio-spatial cognition" for this cognitive capacity. This label suggests a cognitive ability linked to group living, but it is unlikely to be limited to species living in permanent groups. For most animals the ability of tracking the whereabouts of living things, be it conspecifics, prey or predators, will have positive effects on fitness. We assume, however, that the complexity of simultaneously tracking multiple group members selected for additional proficiency.

With the exception of some terrestrial species, most primate groups forage and travel in relatively dense environments. Groups tend to remain coherent in spite of the fact that 
some members cannot see each other over longer periods of time. Coherence can in principle be maintained by three complementary mechanisms: (1) each group member remains in visual contact with at least one other member and a network of visual contacts connects all members of the group; (2) group members are in regular auditory contact with each other, notably by emitting soft vocalisations, usually labelled 'contact calls', and (3) each individual has a mental representation of the location of the members of his group, or at least those in its direct vicinity, even when these move and are silent and out of sight. In this paper we focus on this last and most cognitively challenging aspect of socio-spatial cognition: the ability to mentally represent group members that (1) are out of sight and produce no sounds by which they can be recognized individually and (2) mentally project the path along which invisible and silent group members are likely to move during foraging or travel. The first requires a capacity for object permanence and the second for tracking invisible displacements of objects, both phenomena that were originally defined by Piaget (1937) in the context of human development, albeit that the objects are in our case living animals and that their movements can be much more complicated than the linear object displacements usually tested in experiments on spatial cognition. Relatively few studies used dynamic and animate objects (reviewed in Call 2000; Shettleworth 2010). Exceptions include a study by Bates and colleagues (2008) in which elephants are reported to be able to recognise group members by scent and to track their positions while walking. Wich and De Vries (2006) showed that male langurs have a representation of the membership of their group, but not necessarily of the positions of individual members. In the presence of a predator, the langurs only stopped giving alarm calls when all the individuals had reacted by giving at least one call.

\section{Ecological spatial orientation}

Taking direct routes between different locations in the home range towards goals that are initially not visible has been shown for many primate species, both in the wild (e.g. Boesch and Boesch 1984; Garber 1989; Sigg and Stolba 1981) and in captivity (Ludvig et al. 2003). For example, hamadryas baboons use a least distance strategy and apparently know that they are approaching their goal before seeing it, accelerating their 
pace in anticipation (Sigg and Stolba 1981). Chimpanzees remembered up to 18 different locations during experiments in large enclosures (Menzel 1973). Vervet monkeys could only memorize six distinct food locations during similar experiments, but seemed to anticipate their path three steps ahead, thus solving a simple 'travelling salesman problem' (Cramer and Gallistel 1997). Japanese monkeys made a beeline for akebi fruit at locations where akebi had been found in the previous fruiting season after finding ripe fruit placed on their path ahead of the season (Menzel 1991).

Dear enemies

Vervet monkeys were also shown to possess socio-spatial cognition at a larger scale. Using playback experiments Cheney and Seyfarth (1982b) could show that neighbouring groups were associated with vocalisations from specific directions. This ability to associate locations and individuals was first established in territorial birds and is usually referred to as the 'dear enemy' phenomenon (Fisher 1954), also known as the 'neighbour-stranger' effect. Territorial individuals respond with greater aggression to strangers than to familiar neighbours, implying that they can recognise their neighbours and associate them with a specific territory as was shown in a series of seminal papers by Brooks and Falls (Brooks and Falls 1975a, b; Falls and Brooks 1975). The phenomenon has been shown in numerous species (Akçay et al. 2009; Briefer et al. 2008; Carazo et al. 2008; Leiser and Itzkowitz 1999; Temeles 1994 and references therein; Zenuto 2010), including several primate species (Kitchen and Beehner 2007 and references therein; Thompson et al. 2012).

Invisible displacements

The Piagetian theory on object permanence, including visible and invisible displacements, suggests how children mentally represent out-of-sight objects (Piaget 1937; Piaget and Inhelder 1966). Object permanence and an understanding of visible displacements has been demonstrated in a wide range of vertebrate species, for example primates (de Blois et al. 1998; de Bois and Novak 1994; Deppe et al. 2009; 
Mendes and Huber 2004), domesticated carnivores (Fiset and Doré 2006; Fiset and LeBlanc 2007; Gagnon and Dore 1993), dolphins (Jaakkola et al. 2010) and birds (Bugnyar et al. 2007). The ability to correctly locate invisibly moving objects has, however, only been reported in psittacine birds (Pepperberg et al. 1997), corvids (Bugnyar et al. 2007; Pollok et al. 2000), domesticated carnivores (Collier-Baker et al. 2004; Dumas 1992), monkeys (Mendes and Huber 2004; Neiworth et al. 2003) and great apes (Albiach-Serrano et al. 2010; Barth and Call 2006; Collier-Baker et al. 2006; de Blois et al. 1998), whereby the results of several studies fail to lend unequivocal support to the presence of this cognitive ability in the species studied. Predicting the future positions of moving targets on computer screens, as shown in studies using eyemovements (Ferrera and Barborica 2010 and references therein) is a related skill, but its relevance to movements at the scale considered in this study is less obvious.

Testing socio-spatial cognition in vervets

We tested whether vervet monkeys can mentally follow invisible displacements of silent group members under natural conditions using playbacks of the most commonly uttered vocalisation, the contact grunt. Contact grunts are short range affiliative calls emitted in different contexts: when encountering another member of the group, dominant or subordinate, when moving to an open area, or when another group has just been spotted, as described, among others, by Cheney and Seyfarth (1982a) for vervets and by Rendall and colleagues for baboons (Rendall et al. 1999). Although these grunts tend to show acoustic differences in different contexts, the ones selected for the playbacks were not emitted, during agonistic interactions, during encounters with other groups, or after other strong stimuli of any kind that we were aware of. We assumed the main function of these grunts to be providing information of the whereabouts of the caller to its fellow group members and perhaps also eliciting similar calls from those group members (Fig. 1 gives an example of the calls used).

--- Figure 1 about here --- 
We tested two predictions using methods illustrated in Fig. 2. Prediction 1: vervet monkeys can mentally follow the trajectories of invisible group members, at least over short time spans. In experiment A (Fig. 2A) we played the contact call of an out of sight individual (emitter) to the subject from an 'impossible location', i.e. a location that the individual could not have reached given the distance and available time (test condition) or from a 'possible' location (control condition).

Prediction 2: vervets have a mental representation of the natural movement of other vervets, i.e. they can predict the trajectories of out-of-sight group members based on their experience with their usual speed during specific group activities, notably foraging and travelling, perhaps even taking the local topography into account. In experiment $B$ (Fig. 2B), we played two contact calls of an individual that was out-of-sight during the entire trial (emitter) to the subject, simulating either an impossible (test condition) or a possible (control condition) movement.

-- Fig. 2 about here --

\section{Methods}

Study site and subjects

Subject were members of two non-neighbouring groups of vervet monkeys (Chlorocebus pygerythrus) in the Loskop Dam Nature Reserve, Mpumalanga, South Africa. The reserve, situated $250 \mathrm{~km}$ north east of Johannesburg (-25²6' 31.69", +29 15' 19.14"), covers 25000 ha of bushveld (a mixture of tall grasses and thick acacia bushes). The Donga group had a home range of 224 ha and consisted of 15 individuals and the Picnic group had range of 138 ha and 11 members (for a detailed description see: Barrett et al. 2010). These ranges were separated by about $3 \mathrm{~km}$. Our groups, like most vervet groups, contained multiple adult males and females. Females usually remain in their natal group and form stable hierarchies organised in matrilines, while most males migrate to other groups before reaching sexually maturity. During the habituation period from January till May, data on social behaviour were collected using mainly ad libitum and focal-animal sampling methods (Altmann 1974). This allowed us to 
construct a hierarchy and document affiliative relations between individuals. The preliminary experiments were done in April and experiments A and B from June till September 2005.

\section{Recordings}

Vocalisations of individually recognised individuals were recorded by ML ad libitum with a Sennheiser directional microphone (ME 66) and a Sony digital recorder (DAT TCD D8). We tried to be as close to the emitter as possible (between 3 and 8 meters) without disturbing the animals in their activities. Vocalisations of 13 members of the two study groups were used (details in Table 2). In addition, we used the voices of two females, one adult and one juvenile, recorded at the Vervet Monkey Foundation at Tzaneen, Limpopo Province, South Africa as vocalisations of 'strangers'. Problems with unnatural background noises prevented further use of recordings made at Tzaneen.

\section{Experiments}

Playback trials were done by ML using a Sony recorder (DAT TCD-D8) connected to a 12V Pioneer amplifier working on a small battery and connected to one or two Bose 151 loudspeakers, depending on the type of trial. During the trials the subjects were filmed with a Panasonic digital video camera (NV-GS11) from at least 5 seconds before till 60 seconds after each playback.

Individual recognition by voice is a general phenomenon in animals (Tibbetts and Dale 2007) and has been shown a long time ago in vervets (Cheney and Seyfarth 1980, 1982b).

Nevertheless we verified this in a preliminary experiment that also served to test our equipment, by playing the contact calls recorded at the Tzaneen Vervet foundation to both our study groups as well as calls recorded in one of our study groups to members of the other one. As controls we used all trials with playbacks from 'possible locations' 
of the two experiments A and B (AC, BC1 and BT1 as described below), i.e. all trials with familiar voices played from plausible locations.

For experiment A (Impossible location - Fig 2a), we hid the loudspeaker as soon as a favourable situation presented itself: with at least two individuals well visible and the group resting or foraging. We waited till an individual left the field of vision of the vervet left behind and then played back the contact call of the animal that had disappeared within $2 \mathrm{~min}$ at about 5 meters from the subject tested. The trial was considered as a control (AC) when the moving animal had disappeared from view within $45^{\circ}$ at either side of the loud speaker. All other directions of movement were considered as a test (AT) conditions. The subject was expected to show a sign of surprise in AT-trials, but not in AC-trials.

For experiment B (Unlikely movements - Fig. 2b), two different calls of the same individual that followed each other in the original recording were played from two different loudspeakers with a delay of 5-10 sec. The animal whose voice was used was out-of -sight of the subject tested from the moment the loudspeakers were put in position till the end of the trial. The loudspeakers emitting the first calls in both the control (BC1) and the test condition (BT1) were always in a position concordant with the emitter's last observed position, as in the AC-trials of experiment A. The second call in the control condition (BC2) came from a second loudspeaker placed at less than $1 \mathrm{~m}$ from the first. Only the second call in the test condition (BT2), which came from a location at 7 to $10 \mathrm{~m}$ (depending on the local terrain) from the first and from opposite direction of both the position of the animal whose voice was used and of the loudspeaker emitting the first call (BT1), was expected to produce a strong reaction of surprise.

--- Figure 2 (a) and (b) about here ---

A trial was considered as valid if no unusual event disturbed it, such as a fight, an alarm call, or other event that could change the receiver's attitude and if no vocalisations by any member of the group could be heard shortly before or during the trial. In all those cases, the trial was aborted and no further attempts were made that same day. In order 
to avoid the habituation of monkeys to the experimental procedure no individual was used as test subject in the same experiment more than once a day. Due to the low probability that all the favourable conditions were met, valid trials were infrequent (on average once every three days in each group). We had to use a few subjects in multiple trials (Table 2), but otherwise pseudo-reciprocity was avoided as much as possible by using both vocalisations of different individuals and different vocalisations of the same individual.

--- Table 2 about here ---

Video analysis

A quick and radical change of behaviour immediately after the playback served as our main criterion for the presence or absence of a reaction associated with 'surprise', shorthand for a reaction to an unusual and/or unexpected event. The end of the reaction period was defined by a return to the initial activity or another routine activity for more than five seconds. The videos were analysed by ML and four naive observers that were all experienced observers of vervet behaviour, but did not know whether they looked at a test or control trial. The videos were muted, except for a 'beep' when the vocalisation was played and were analysed in random order. We used both qualitative and quantitative variables: we scored the degree of reaction and the instantaneity of the reaction and measured the duration of the reaction and the number of head rotations (Table 3). Kendall's tau-b between ML and the observers: EW: 0.783; CF: 0.664; AB: 0.659; YG: 0.775. In addition we asked YG to measure the instantaneity of the reaction (Cohen's kappa: 0.886) and the number of head rotations (Pearson r: 0.996). On the basis of the high level of agreement we decided to use ML's original scores for the analysis.

--- Table 3 ---

Statistical analysis 
The differences between test and control conditions were examined at the individual level using Mann-Whitney $\mathrm{U}$ and Wilcoxon tests for quantitative variables and Fisher tests for qualitative variables (Siegel and Castellan 1988). For individuals tested more than once we used the average score for quantitative variables and the result of the first trial for qualitative variables. The alpha-level was set at 0.05 , but whenever datasets were used in two different tests, a Bonferroni corrected alpha of 0.025 was used. Exact p-values were calculated for small sample sizes (Mundry and Fischer 1998). Tests are two-tailed unless indicated otherwise. Data analysis was carried out with SPSS 18.0.

The AC trials were difficult to perform and therefore only a few of them were done with different subjects. We checked if all trials from the different experiments in which the playback came from a 'possible location' could be pooled together by performing a Kruskal Wallis test, since these trials are de facto identical in design . We only used the reactions to the first playbacks in the experiment $B$ (with two loudspeakers) to prevent a possible effect of a redundant stimulus. The tests revealed no significant differences across conditions for the number of head rotations $(H(2)=3.55, p=0.169)$ and the reaction length $(\mathrm{H}(2)=3.79, \mathrm{p}=0.150)$. We therefore decided to pool these data to supplement our analyses when needed.

\section{Results}

Preliminary experiment: group member - stranger discrimination

We compared reactions to the playbacks of strangers with reactions to the playbacks of group members broadcasted from a possible location. When hearing the vocalisation of a stranger, the vervets showed a significantly stronger reaction (Fisher's exact test: $\mathrm{N}=$ $9, p=0.016$ and with the controls pooled $N=22, p=0.029$ ), responded faster (Fisher's exact test: $N=9, p=0.047$ and with the controls pooled $N=22, p=0.054$ ), with more head rotations (Mann-Whitney test: one-tailed, $N$ stranger $=5, N$ controls pooled $=11, U$ $=0, \mathrm{z}=-3.17, \mathrm{p}_{\text {exact }}=0.0002$ ) and it took longer before they returned to their daily routine (Mann-Whitney test: one-tailed, $\mathrm{N}$ stranger $=5, \mathrm{~N}$ controls pooled $=11, \mathrm{U}=0, \mathrm{z}$ $=-3.14, \mathrm{p}_{\text {exact }}=0.0002$ ). 
--- Figure 3 about here ---

Experiment A: impossible location

We conducted ten test trials with eight different stationary individuals (3AF, 4AM and 1 JF) as subjects. As 'possible location' controls we used only the four control trials from experiment $A$ as well as all 17 control trials pooled from experiment $A$ and $B$. Reactions to impossible locations were stronger (Fisher's exact tests: $N=12, p=0.002$; with the controls pooled $\mathrm{N}=25, \mathrm{p}=0.005$ ), faster (Fisher's exact test: $\mathrm{N}=12, \mathrm{p}=0.018$; with the controls pooled $\mathrm{N}=25, \mathrm{p}=0.022$ ), lasted longer (Mann-Whitney test: one-tailed, $\mathrm{U}=0, \mathrm{z}$ $=-2.74, \mathrm{p}_{\text {exact }}=0.002$; with the controls pooled, one-tailed, $\mathrm{U}=2, \mathrm{z}=-3.49, \mathrm{p}_{\text {exact }}=$ 5.3x10-3) and the number of head rotations was higher (Mann-Whitney test: one-tailed, $\mathrm{U}=0.5, \mathrm{z}=-2.65, \mathrm{p}_{\text {exact }}=0.004$; with the controls pooled, one-tailed, $\mathrm{U}=6.5, \mathrm{z}=-3.13$, $p_{\text {exact }}=5.3 \times 10^{-3}$ ). For three subjects we had matched test and control trials in which the voice of the same individuals were used. The subject's reaction was stronger for all parameters in the test trials compared to the control trials.

--- Figure 4 about here ---

Experiment B: unlikely movements

We first tested the reaction to an impossibly fast movement of an invisible individual by comparing the reactions to the sound of the first loudspeaker (BT1) with the reactions to the sound coming from the opposite direction (BT2) for eight individuals (with the emitters of the voice used always out-of-sight). The sounds coming from the opposite direction elicited reactions that were stronger (Fisher's exact test: $N=16, p=0.014$ ), but not faster (Fisher's exact test: $\mathrm{N}=16, \mathrm{p}=0.47$ ), lasted longer (Wilcoxon signed rank-test: one-tailed, $\mathrm{Z}=-2.52, \mathrm{~N}=8$, $\mathrm{p}_{\text {exact }}=0.0039$ ) and were followed by a higher the number of head rotations (Wilcoxon signed rank- test: one-tailed, $\mathrm{Z}=-2.52, \mathrm{~N}=8, \mathrm{p}_{\text {exact }}$ $=0.0039$ ). As a control, we confronted five different subjects with two different 
recordings (BC1 and $\mathrm{BC} 2$ ) of vocalisations of a same individual emitted at the same interval as used in the test trials from two loudspeakers that were placed close to each other and were both at a plausible location. The degree of reaction to the two sounds was not significantly different based on the judgement of surprise (Fisher's exact test: $\mathrm{N}$ $=10, \mathrm{p}=1$ ), the instantaneity of the reaction (Fisher's exact test: $\mathrm{N}=10, \mathrm{p}=1$ ), the total time before returning to routine behaviour (Wilcoxon signed rank-test: one-tailed, $\mathrm{Z}=$ $0.73, \mathrm{~N}=8, \mathrm{p}_{\text {exact }}=0.31$ ) and the number of head rotations (Wilcoxon signed rank-test: one-tailed, $\mathrm{Z}=-0.55, \mathrm{~N}=8, \mathrm{p}_{\text {exact }}=0.37$ ).

Finally, we compared the second playbacks from the test (BT2) and control (BC2) trials. The degree of reaction to the test trials only showed an insignificant trend of being stronger (Fisher's exact test: $\mathrm{N}=13 \mathrm{p}=0.084$ ). However, the reaction was significantly faster (Fisher's exact test: $N=13, p=0.007$ ), lasted longer (Mann Whitney test: onetailed, $U=4, z=-2.35$, $p_{\text {exact }}=0.0093$ ) and the number of head rotations was higher (Wilcoxon signed rank- test: one-tailed, $\mathrm{U}=6.4, \mathrm{z}=-2.00, \mathrm{~N}=8, \mathrm{p}_{\text {exact }}=0.021$, Bonferroni corrected $\alpha=0.025$ ). As in experiment $A$, we could also compare the results for test and control trials with the same voice for three subjects. The results were in line with the complete set.

--- Figure 5 about here ---

\section{Discussion}

Following out-of-sight movements

In experiment $A$, we played the emitter's voice to the subject after the emitter had left the subject's visual field. During test trials in which a vocalisation was played back from a different direction than the one in which the emitter had left, we observed a significantly stronger reaction than in control trials in which we played the emitter's voice from the direction in which (s)he moved out-of-sight. This was also true for trials in which we used the vocalisation of only one of several individuals that had just disappeared from sight. Subjects generally showed little or no reaction to the playbacks during control trials. However, they sometimes replied to the playback with a contact 
call, but without looking up and without showing a surprised reaction. This suggests to us that the vervets considered this situation as a routine event. The subject could only have been updated about the emitter's real position by movements of the vegetation and non-vocal sounds caused by the emitter's movements, but such clues do not allow individual recognition and thus do not invalidate a test of the ability of tracking invisible displacements. We therefore conclude that the subjects expectations were violated, which suggests that vervets are able to track the movements of group members at least for a few minutes after they disappear from sight. This is in agreement with studies on target tracking by monkeys (Ferrera and Barborica 2010; Filion et al. 1996; Neiworth et al. 2003; Washburn and Rumbaugh 1992), but in contradiction with some studies on invisible displacement suggesting that monkeys cannot represent out of sight movements (Call 2000; de Blois et al. 1998; de Bois and Novak 1994; Gomez 2005; Natale et al. 1986 and references therein).

Implausible speed

In experiment $B$, contact calls were played back from two directions, diametrically opposed from the point of view of the receiver (test condition) or from two locations very close to one another (control condition). The movements suggested by the test trials were highly implausible, because a real monkey would have had to run through the open area around the subject, or run extremely fast behind the vegetation surrounding the subject, to get from one speaker position to the next within this time frame. The subjects clearly showed reactions of surprise in the test trials but not in the controls. No difference between the first and the second playback (BT1 and BT2) was found for the parameter 'instantaneity of the reaction'. This can be due to the binary character of the parameter used (reaction within a second or not) combined with a small sample size. However, the reactions were overall still stronger, lasted longer, and involved more head rotations. We conclude that the subjects' expectations about the speed with which conspecifics can move from one location to the next were violated. This goes beyond the results of Hauser (1998), who showed in a lab experiment that tamarins expect animals to move to other locations when out of sight, but not inanimate objects. 
A less cognitively demanding hypothesis would be that the subjects do not represent the movements of group members but know that an individual cannot occupy two positions at the same time. In contrast to the experiment $A$, in which the departure of the emitter indicated a movement in a particular direction, the two vocalisations of experiment B only gave indications about two static locations. We cannot exclude that this just represents a violation of expectations about the same individual being at two distant locations rather than about movement. Nevertheless, we feel that 'implausible speed' and 'unlikely movement' are appropriate terms. Our reasoning is as follows: The simplest explanation for a surprise reaction after hearing the same voice from two different locations is that it violates the day-to-day experience of the animals: the same voice can be heard from different locations, but not normally with such a short time interval, at least not without any sign of an individual moving fast. Hearing the same sound from different locations at short intervals does occur occasionally, however: vervets sometimes run from one spot to the next while vocalising and screaming infants tumble from trees at times. Such natural events always involve fast, and therefore rather conspicuous, displacements. Thus, what surprises them is less likely to be the fact that the two sounds come from different locations shortly after each other as such, but rather the lack of fast movements and sounds that normally accompany this.

\section{A functional perspective}

The question is whether a monkey tracking a group member's movement in the wild can be compared to tracking an object, animated or inanimate, in the lab. Loosing track of an object does not normally have any serious fitness consequences, but losing track of one's group members can have serious, even fatal, consequences. The two types of experiments are therefore hard to compare in terms of ecological validity. Tracking group members in dense environments can be essential during encounters with sit-andwait predators when all members of the group try to move away silently (Zuberbühler and Jenny 2002). It may even be used to keep track of the predators themselves. Sociospatial skills might also play a role in coordinating group movement (King and Sueur 2011), in cooperative group defence against neighbouring groups (Kitchen and Beehner 2007; Meunier et al. 2012), or in more complex coordinated actions such as 'co- 
operative' hunting (Newton-Fisher 2007). These forms of coordination do not necessarily imply complex mental representations or shared internal processes (Barrett et al. 2007; Knoblich and Jordan 2003). Socio-spatial cognition can also be important for following of the positions of potential allies or competitors. Some authors noted that individuals adopt different strategies in competitive situations depending on the identity of individuals in their surroundings (Janson 1990; Robinson 1981; Seyfarth and Cheney 2000). Finally, it might be useful for individuals that have an interest in withholding information. Chimpanzee females can, for example, refrain from giving a greeting grunt to a male when the alpha male is around (Laporte and Zuberbühler 2010). Experiments conducted by Seyfarth and Cheney (1984) suggested that vervets are more attentive to the movements of kin and individuals with which they recently had an affiliative interaction. We had the impression that our subjects kept track of all the individuals in their direct vicinity, independently of age, sex, rank or degree of kinship.

\section{Acknowledgements}

We thank the Mpumalanga Parks Board for permission and the University of South Africa (UNISA) for logistic support. Many thanks also to the Applied Behavioural Ecology and Ecosystems Research Unit (ABEERU) colleagues, L. Brown, L. Barrett, S. P. Henzi, and R. Bshary, who provided essential support. We thank E. Sarroca, C. Scheid, J. Laporte and F. de Castilla for assistance in the field and A. Barrett, C. Fruteau, E. Van de Waal and especially Yan Gobrecht for video-based analysis. L. Barret, R. Byrne, J. Call, J. C. Gómez and K. Zuberbuhler provided helpful comments on earlier drafts. Constructive comments by L. Barrett and an anonymous reviewer helped to improve our text. CNRS ESF-EUROCORES program OMLL (CRP JA33) and NWO program Evolution and Behaviour (051-12-036) provided financial support. 


\section{References}

Akçay Ç, Wood WE, Searcy WA, Templeton CN, Campbell SE, Beecher MD (2009) Good neighbour, bad neighbour: song sparrows retaliate against aggressive rivals. Anim Behav 78:97-102

Albiach-Serrano A, Call J, Barth J (2010) Great apes track hidden objects after changes in the objects' position and in subject's orientation. Am J Primatol 72:349-359

Altizer S, Nunn CL, Thrall PH, Gittleman JL, Antonovics J, Cunningham AA, Cunnningham AA, Dobson AP, Ezenwa V, Jones KE (2003) Social organization and parasite risk in mammals: integrating theory and empirical studies. Ann Rev Ecol Evol Syst 34:517-547

Altmann J (1974) Observational study of behavior: sampling methods. Behaviour 49:227-267

Barrett AS, Brown LR, Barrett L, Henzi P (2010) A floristic description and utilisation of two home ranges by vervet monkeys in Loskop Dam Nature Reserve, South Africa. Koedoe $52: 1-12$

Barrett L, Henzi P, Rendall D (2007) Social brains, simple minds: does social complexity really require cognitive complexity? Phil Trans Royal Soc B 362:561-575

Barth J, Call J (2006) Tracking the displacement of objects: a series of tasks with great apes (Pan troglodytes, Pan paniscus, Gorilla gorilla, and Pongo pygmaeus) and young children (Homo sapiens). J Exp Psychol: Animal Behavior Processes 32:239

Bates LA, Sayialel KN, Njiraini NW, Poole JH, Moss CJ, Byrne RW (2008) African elephants have expectations about the locations of out-of-sight family members. Biol Lett 4:34-36

Bergman TJ, Beehner JC, Cheney DL, Seyfarth RM (2003) Hierarchical classification by rank and kinship in baboons. Science 302:1234-1236

Boesch C, Boesch H (1984) Mental map in wild chimpanzees: an analysis of hammer transports for nut cracking. Primates 25:160-170

Briefer E, Rybak F, Aubin T (2008) When to be a dear enemy: flexible acoustic relationships of neighbouring skylarks, Alauda arvensis. Anim Behav 76:1319-1325

Brooks RJ, Falls JB (1975a) Individual recognition by song in white-throated sparrows .1. Discrimination of songs of neighbors and strangers. Can J Zool 53:879-888

Brooks RJ, Falls JB (1975b) Individual recognition by song in white-throated sparrows .3. Song features used in individual recognition. Can J Zool 53:1749-1761

Bugnyar T, Stöwe M, Heinrich B (2007) The ontogeny of caching in ravens, Corvus corax. Anim Behav 74:757-767

Call J (2000) Representing space and objects in monkeys and apes. Cogn Sci 24:397-422

Carazo P, Font E, Desfilis E (2008) Beyond 'nasty neighbours' and 'dear enemies'? Individual recognition by scent marks in a lizard (Podarcis hispanica). Anim Behav 76:1953-1963 
Cheney DL, Seyfarth RM (1980) Vocal recognition in free-ranging vervet monkeys. Anim Behav 28:362-367

Cheney DL, Seyfarth RM (1982a) How vervet monkeys preceive their grunts: field playback experiments. Anim Behav 30:739-751

Cheney DL, Seyfarth RM (1982b) Recognition of individuals within and between groups of freeranging vervet monkeys. Am Zool 22:519-529

Cheney DL, Seyfarth RM (1987) The influence of intergroup competition on the survival and reproduction of female vervet monkeys. Behav Ecol Sociobiol 21:375-386

Cheney DL, Seyfarth RM (1990) How monkeys see the world. University of Chicago Press, Chicago

Clutton-Brock TH, Harvey PH (1980) Primates, brains and ecology. J Zool 190:309-323

Collier-Baker E, Davis JM, Nielsen M, Suddendorf T (2006) Do chimpanzees (Pan troglodytes) understand single invisible displacement? Anim Cogn 9:55-61

Collier-Baker E, Davis JM, Suddendorf T (2004) Do dogs (Canis familiaris) understand invisible displacement? J Comp Psychol 118:421-433

Cramer AE, Gallistel CR (1997) Vervet monkeys as travelling salesmen. Nature 387:464

Dasser V (1988) A social concept in Java monkeys. Anim Behav 36:225-230

de Blois ST, Novak MA, Bond M (1998) Object permanence in orangutans (Pongo pygmaeus) and squirrel monkeys (Saimiri sciureus). J Comp Psychol 112 (2):137

de Bois ST, Novak MA (1994) Object permanence in rhesus monkeys (Macaca mulatta). J Comp Psychol 108:318

Deppe AM, Wright PC, Szelistowski WA (2009) Object permanence in lemurs. Anim Cogn 12:381-388

Dumas C (1992) Object permanence in cats (Felis catus) - an ecological approach to the study of invisible displacements. J Comp Psychol 106:404-410

Dunbar RIM (1992) Neocortex size as a constraint on group size in primates. J hum Evol 20: 469-493

Dunbar RIM (1998) The social brain hypothesis. Evol Anthrop 6:178-190

Dunbar RIM (2003) Evolution of the social brain. Science 302:1160-1161

Dunbar RIM, Shultz S (2007) Evolution in the social brain. Science 317:1344-1347

Falls JB, Brooks RJ (1975) Individual recognition by song in white-throated sparrows .2. Effects of location. Can J Zool 53:1412-1420

Ferrera VP, Barborica A (2010) Internally generated error signals in monkey frontal eye field during an inferred motion task. J Neurosci 30:11612-11623

Filion CM, Washburn DA, Gulledge JP (1996) Can monkeys (Macaca mulatta) represent invisible displacement? J Comp Psychol 110:386-395 
Fiset S, Doré FY (2006) Duration of cats' (Felis catus) working memory for disappearing objects. Anim Cogn 9:62-70

Fiset S, LeBlanc V (2007) Invisible displacement understanding in domestic dogs (Canis familiaris): the role of visual cues in search behavior. Anim Cogn V10:211-224

Fisher J (1954) Evolution and bird sociality. In: J. Huxley, Hardy A, Ford E (eds) Evolution as a process. Allen \& Unwin, London, pp 71-83

Gagnon S, Dore FY (1993) Search behavior of dogs (Canis familiaris) in invisible displacement problems. Anim Learn Behav 21:246-254

Garber PA (1989) Role of spatial memory in primate foraging patterns: Saguinus mystax and Saguinus fuscicollis. Am J Primatol 19:203-216

Gomez J-C (2005) Species comparative studies and cognitive development. Trends Cogn Sci 9:118-125

Harvey PH, Bennett PM (1983) Brain size, energetics, ecology and life-history patterns. Nature 306:314-315

Hauser MD (1998) A nonhuman primate's expectations about object motion and destination: The importance of self-propelled movement and animacy. Dev Sci 1:31-37

Humphrey NK (1976) The social function of intellect. In: Bateson PPG, Hinde RA (eds) Growing Points in Ethology. Cambridge University Press, Cambridge, pp 303-317

Jaakkola K, Guarino E, Rodriguez M, Erb L, Trone M (2010) What do dolphins (Tursiops truncatus) understand about hidden objects? Anim Cogn 13:103-120

Janson CH (1990) Social correlates of individual spatial choice in foraging groups of brown capuchin monkeys, Cebus apella. Animal Behaviour 40:910-921

King A, Sueur C (2011) Where next? Group coordination and collective decision making by primates. Int J Primatol 32:1245-1267

Kitchen DM, Beehner JC (2007) Factors affecting individual participation in group-level aggression among non-human primates. Behaviour 144:1551-1581

Knoblich G, Jordan JS (2003) Action coordination in groups and individuals: Learning anticipatory control. J Exp Psychol-Learning Memory and Cognition 29:1006-1016

Laporte MNC, Zuberbühler K (2010) Vocal greeting behaviour in wild chimpanzee females. Anim Behav 80:467-473

Leiser JK, Itzkowitz M (1999) The benefits of dear enemy recognition in three-contender convict cichlid (Cichlasoma nigrofasciatum) contests. Behaviour 136:983-1003

Ludvig N, Tang HM, Eichenbaum H, Gohil BC (2003) Spatial memory performance of freelymoving squirrel monkeys. Behav Brain Res 140:175-183

Mendes N, Huber L (2004) Object permanence in common marmosets (Callithrix jacchus). J Comp Psychol 118:103 
Menzel CR (1991) Cognitive aspects of foraging in Japanese monkeys. Anim Behav 41:397-402

Menzel EW (1973) Chimpanzee spatial memory organization. Science 182:943-945

Meunier H, Molina-Vila P, Perry S (2012) Participation in group defence: proximate factors affecting male behaviour in wild white-faced capuchins. Anim Behav 83:621-628

Mundry R, Fischer J (1998) Use of statistical programs for nonparametric tests of small samples often leads to incorrect $P$ values: examples from Animal Behaviour. Anim Behav 56:256259

Natale F, Antinucci F, Spinozzi G, Potì P (1986) Stage 6 object permanence in nonhuman primate cognition: A comparison between gorilla (Gorilla gorilla) and Japanese macaque (Macaca fuscata). J Comp Psychol 100:335-339

Neiworth JJ, Steinmark E, Basile BM, Wonders R, Steely F, DeHart C (2003) A test of object permanence in a new-world monkey species, cotton top tamarins (Saguinus oedipus). Anim Cogn 6:27-37

Newton-Fisher N (2007) Chimpanzee Hunting Behavior. In: Henke W, Tattersall I (eds) Handbook of Paleoanthropology, vol 2. Springer, Berlin Heidelberg, pp 1295-1320

Nunn C, Thrall P, Stewart K, Harcourt A (2008) Emerging infectious diseases and animal social systems. Evol Ecol 22:519-543

Pepperberg IM, Willner MR, Gravitz LB (1997) Development of Piagetian object permanence in grey parrot (Psittacus erithacus). J Comp Psychol 111:63

Piaget J (1937) La construction du réel chez l'enfant. Delachaux \& Niestlé, Neuchâtel

Piaget J, Inhelder B (1966) La psychologie de l'enfant. Presses Universitaires de France, Paris

Pollok B, Prior H, Güntürkün O (2000) Development of object permanence in food-storing magpies (Pica pica). J Comp Psychol 114:148-157

Range F, Noë R (2005) Can simple rules account for the pattern of triadic interactions in juvenile and adult female sooty mangabeys? Anim Behav 69:445-452

Rendall D, Seyfarth RM, Cheney DL, Owren MJ (1999) The meaning and function of grunt variants in baboons. Anim Behav 57:583-592

Robinson JG (1981) Spatial structure in foraging groups of wedge-capped capuchin monkeys Cebus nigrivittatus. Anim Behav 29:1036-1056

Sawaguchi T (1992) The size of the neocortex in relation to ecology and social structure in monkeys and apes. Folia primatol 58:131-145

Seyfarth RM, Cheney DL (1984) Grooming, alliances and reciprocal altruism in Vervet monkeys. Nature 308:541-543

Seyfarth RM, Cheney DL (2000) Social awareness in monkeys. Am Zoologist 40:902-909

Shettleworth SJ (2010) Cognition, Evolution and Behavior. 2nd edn. Oxford University Press, New York 
Shultz S, Dunbar RIM (2007) The evolution of the social brain: anthropoid primates contrast with other vertebrates. Proc Royal Soc B 274:2429-2436

Shultz S, Opie C, Atkinson QD (2011) Stepwise evolution of stable sociality in primates. Nature 479:219-222

Siegel S, Castellan NJ (1988) Nonparametric statistics for the behavioral sciences. 2nd edn. McGraw Hill, New York

Sigg H, Stolba A (1981) Home range and daily march in a Hamadryas baboon troop. Folia primatol 36:40-75

Sterck EHM, Watts DP, van Schaik CP (1997) The evolution of female social relationships in nonhuman primates. Behav Ecol Sociobiol 41:291-309

Temeles EJ (1994) The role of neighbours in territorial systems: when are they 'dear enemies'? Anim Behav 47:339-350

Thompson CL, Norconk MA, Whitten PL (2012) Why fight? Selective forces favoring betweengroup aggression in a variably pair-living primate, the white-faced saki (Pithecia pithecia). Behaviour 149:795-820

Tibbetts EA, Dale J (2007) Individual recognition: it is good to be different. Trends Ecol Evol 22:529-537

van Schaik CP (1983) Why are diurnal primates living in groups? Behaviour 87:120-144

van Schaik CP, van Hooff JARAM (1983) On the ultimate causes of primate social systems. Behaviour 85:91-117

Washburn DA, Rumbaugh DM (1992) Comparative assessment of psychomotor performance: target prediction by humans and macaques (Macaca mulatta). J Exp Psychol: General 121:305-312

Whiten A, Byrne RW (1988) Tactical deception in primates. Behav Brain Sci 11:233-244

Wich SA, Vries Hd (2006) Male monkeys remember which group members have given alarm calls. Proc Royal Soc B 273:735 - 740

Zenuto RR (2010) Dear enemy relationships in the subterranean rodent Ctenomys talarum: the role of memory of familiar odours. Anim Behav 79 (6):1247-1255

Zuberbühler K, Jenny D (2002) Leopard predation and primate evolution. J Human Evol 43:873886 
Experiment Voice owner Subject Tested

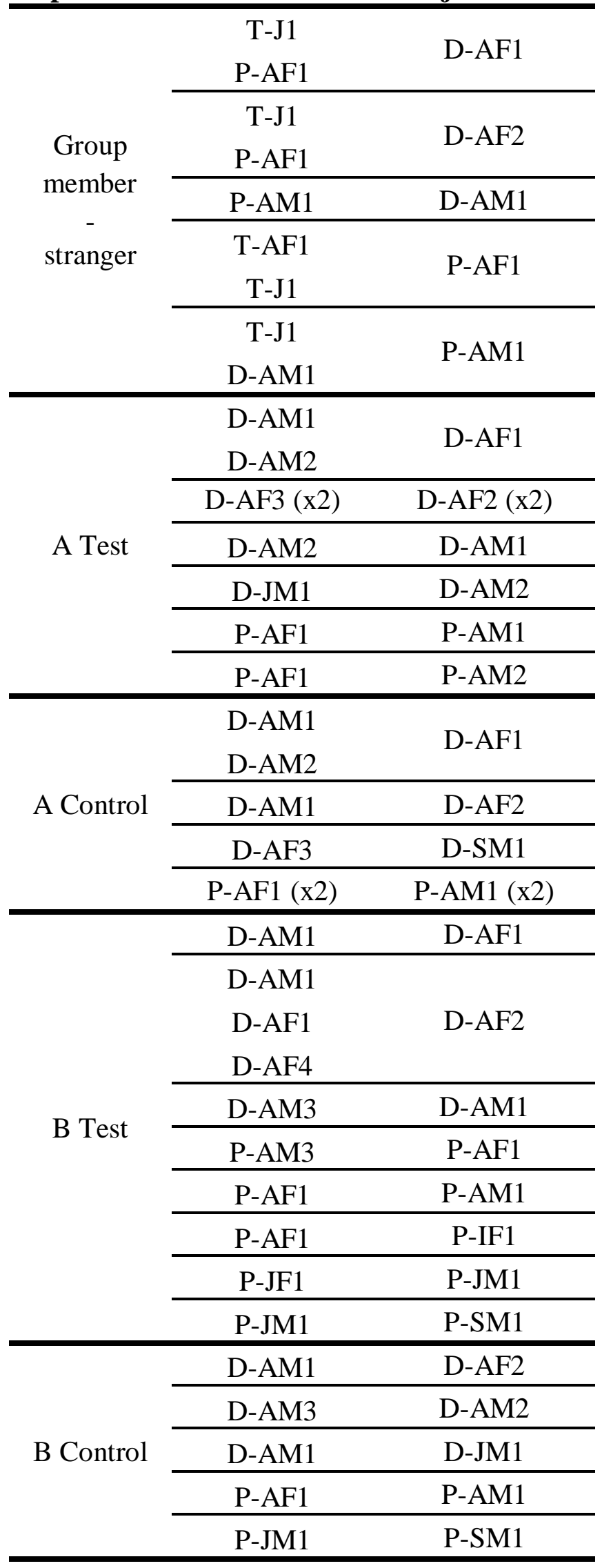

Table 1. Voice owners and subjects tested per experiment. $\mathrm{T}=$ Tzaneen Vervet Monkey Foundation; D = Donga group; $\mathrm{P}=$ Picnic group;. $\mathrm{M}=$ male; $\mathrm{F}=$ female; $\mathrm{A}=$ adult; $\mathrm{S}=$ subadult (males only); $\mathrm{J}=$ juvenile; $\mathrm{I}=$ infant. (x2): Two trials in the same experiment with the same voice owner and the same subject. The results for the same subject in the same experiment were pooled together irrespective of voice owner identity. 


\begin{tabular}{ll}
\multicolumn{1}{c}{ Variable } & \multicolumn{1}{c}{ Definition } \\
\hline Intensity of reaction & 1: No reaction \\
& $\begin{array}{l}\text { 2: Stops activity, several head rotations; and/or } \\
\text { stands bipedally } \\
\text { 3: Stops activity, multiple abrupt head movements, } \\
\text { stands bipedally and/or moves }\end{array}$ \\
\hline $\begin{array}{l}\text { Instantaneity of } \\
\text { reaction }\end{array}$ & $\begin{array}{l}\text { 0: No reaction, or first head movement occurs more } \\
\text { than one second after the emission of the playback } \\
\text { 1: First head movement or standing occurs less than } \\
\text { one second after the emission of the playback }\end{array}$ \\
\hline Number of head & $\begin{array}{l}\text { Number of times the animal stops turning the head } \\
\text { and gazes in a specific direction while scanning the } \\
\text { environment. }\end{array}$ \\
\hline Reaction length & $\begin{array}{l}\text { Duration of head rotations until the individual goes } \\
\text { back to his previous activity (feeding, grooming, etc) } \\
\text { or disappears from sight. This was limited to 60 } \\
\text { seconds of analysis because individuals then tend to } \\
\text { move and it becomes very difficult to assess their } \\
\text { behaviour without disrupting them. }\end{array}$ \\
\hline
\end{tabular}

Table 2. Definitions of the variables used in the statistical analyses. 

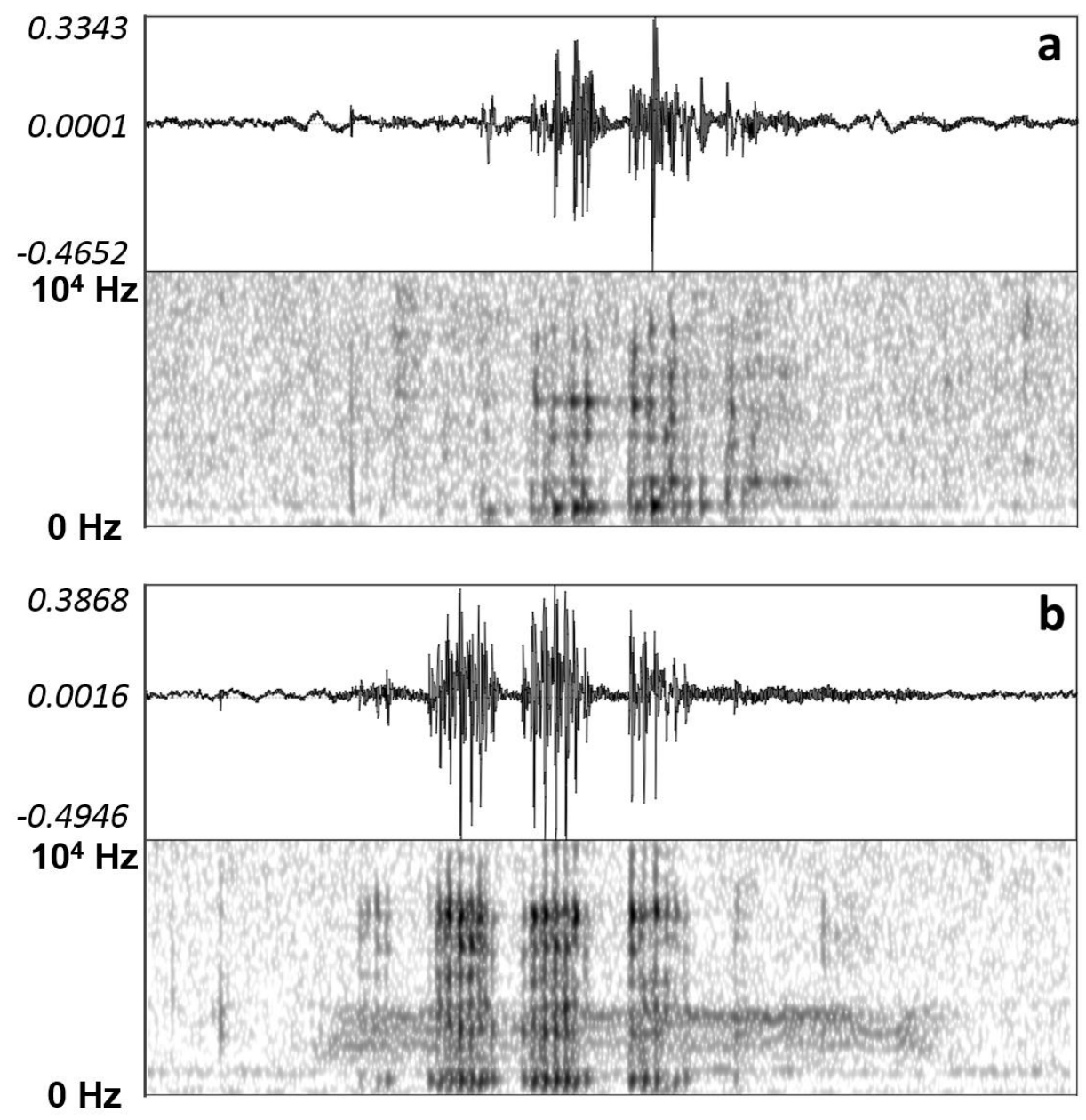

Figure 1. Grunts from (a) an adult female (Gaia, Picnic group) and (b) an adult male (Elvis, Donga group). 

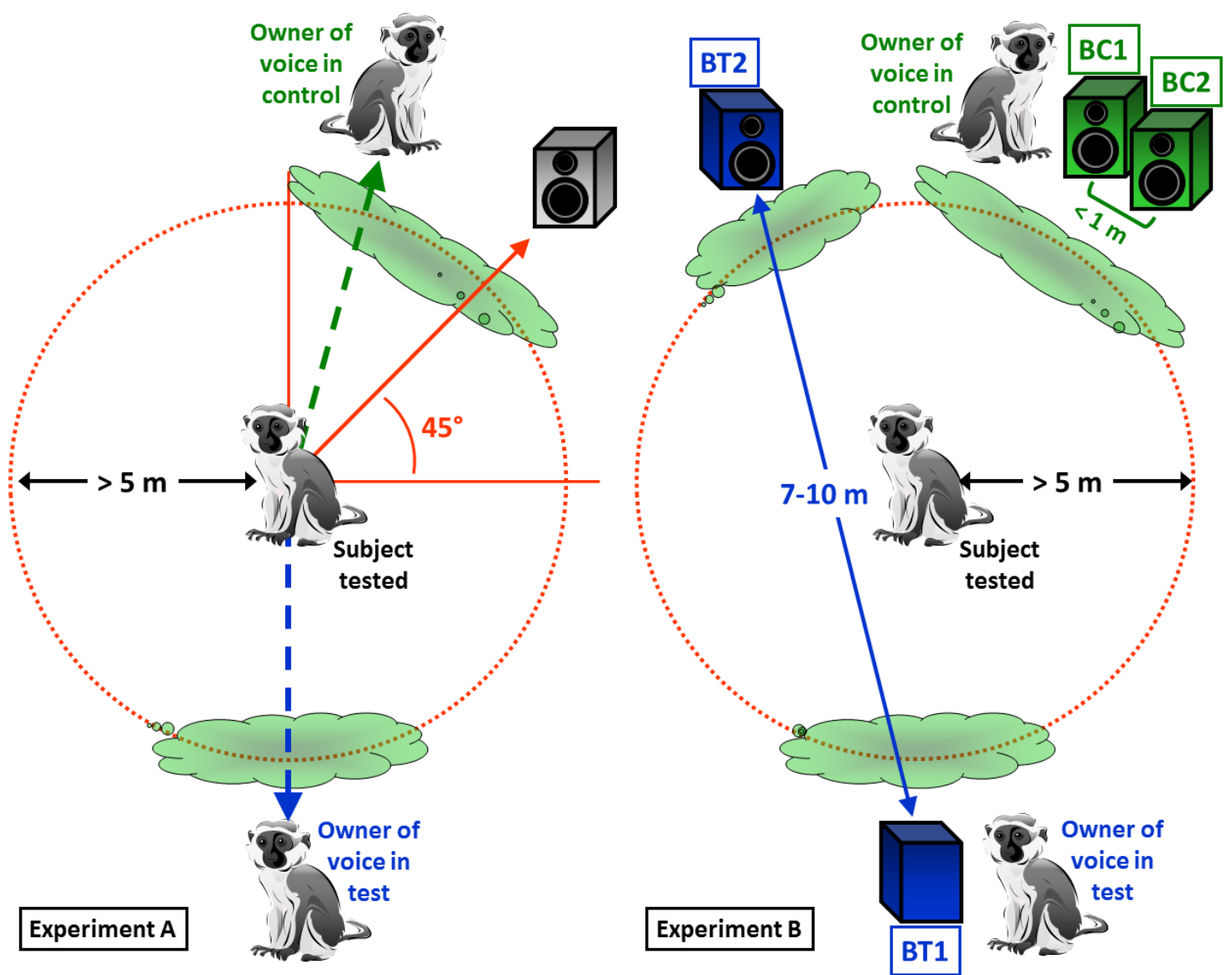

Figure 2. Experimental set-ups.

Experiment A: The subject remains in an open area, the voice of an animal that disappeared from the sugject's field of vision is played back from a hidden loudspeaker. Control condition (AC): the voice owner passes within $45^{\circ}$ at either side of the loudspeaker. Test condition (AT): the voice owner disappears in any other direction.

Experiment B: The subject hears two different calls from the same recording of a single group member with a short time interval from two different loudspeakers. Control condition: the two hidden loudspeakers are placed less than $1 \mathrm{~m}$ apart (BC1 and BC2) that are both in a direction in which the invisible owner of the voice coudl plausibly be. Test condition: The first call ((BT1) comes from a loudspeaker placed as the two speakers in the Control condition, but the second call (BT2) comes from a loudspeaker hidden in the opposite direction from the point of view of the subject. 

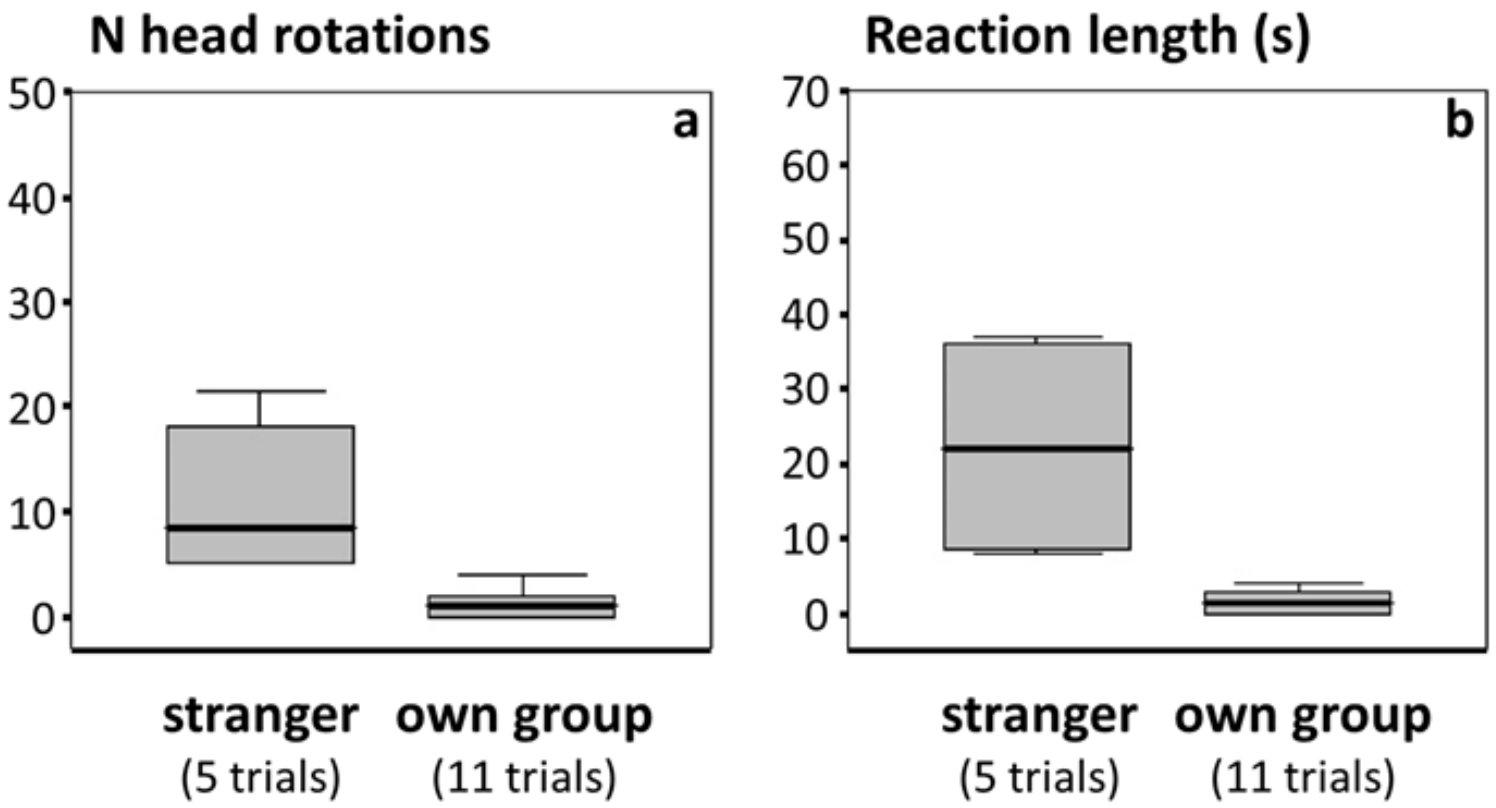

Figure 3. Results of the group member - stranger experiment. Mean (bold lines); upper and lower quartiles (shaded boxes), minimum and maximum values except outliers (whiskers) and outliers, i.e. more than 1.5 times upper quartile (asterix). 
$\mathbf{N}$ head rotations
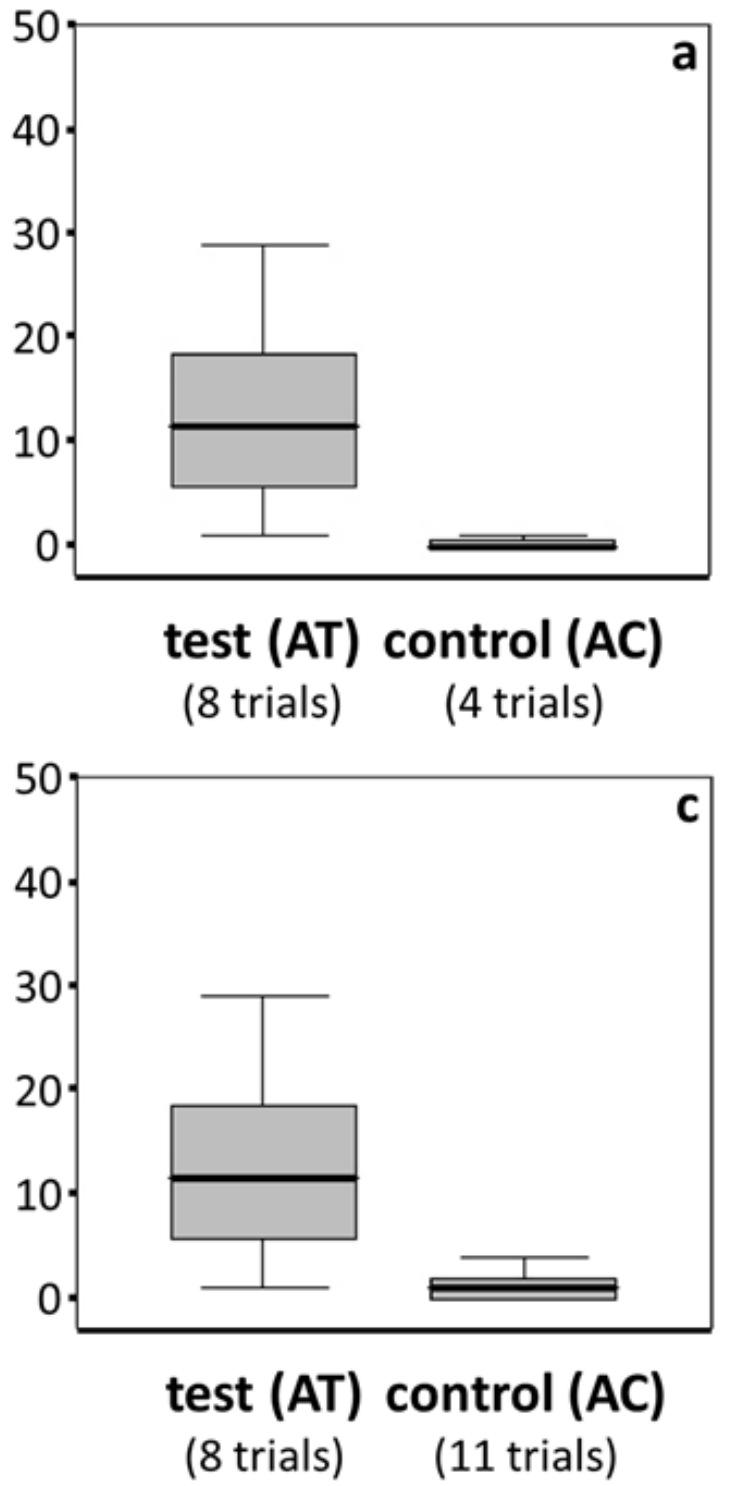

Reaction length (s)
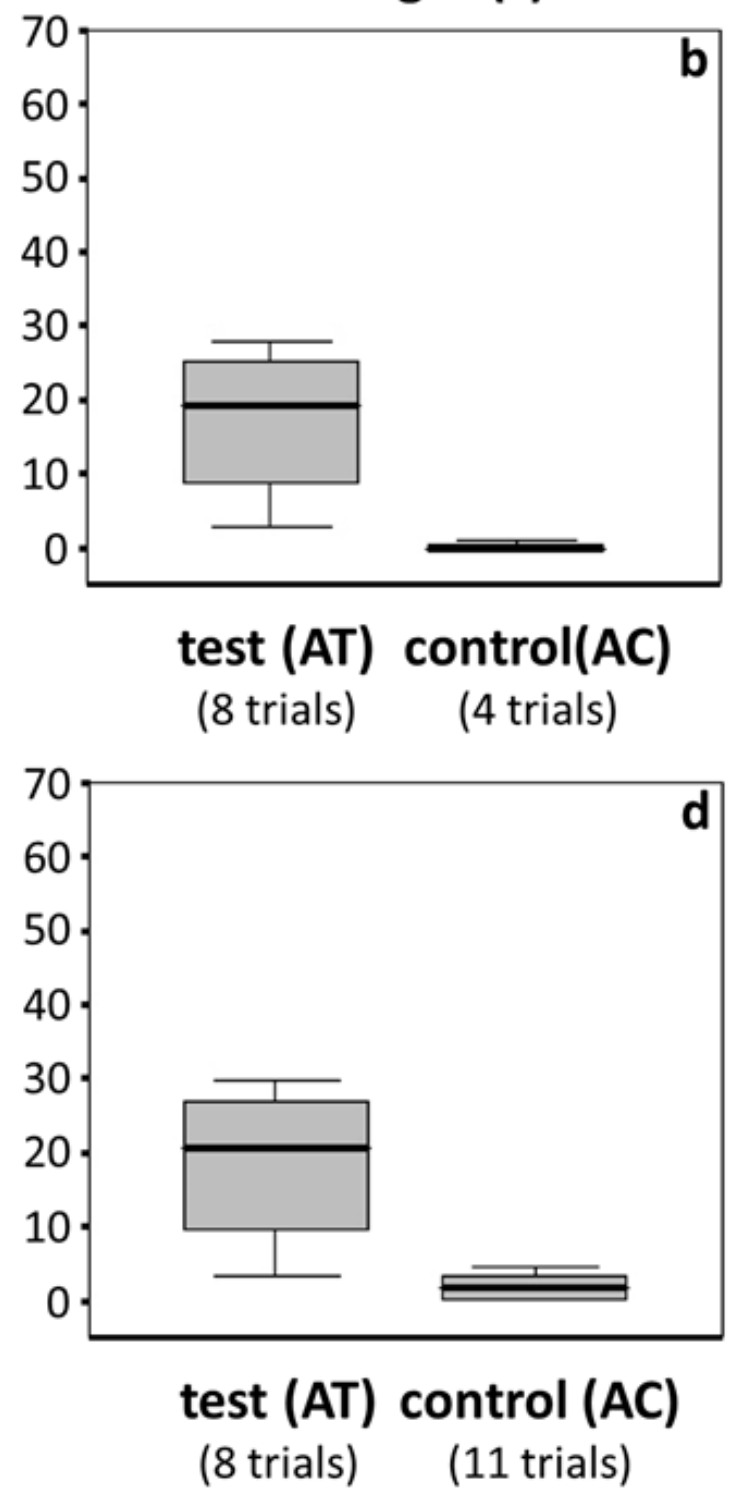

Figure 4. Results of Experiment A - impossible locations. Upper panels a and b: four controls from Experiment A (AC) only; lower panels $\mathrm{c}$ and d: 11 controls from Experiments A and B pooled together (AC, BC1 and BC2). Graph conventions as for Fig. 3. 

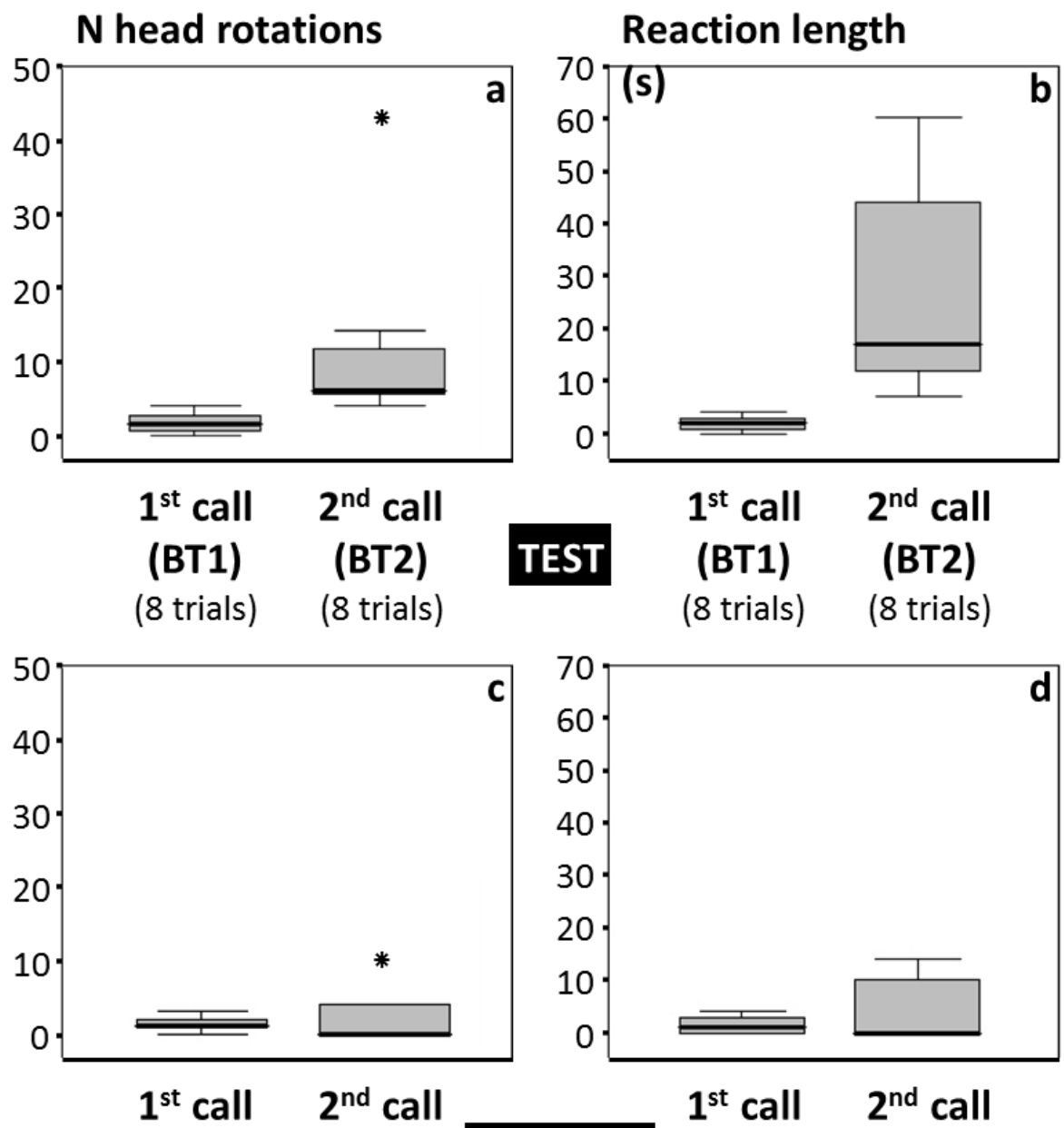

(BC1)

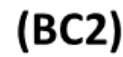

(5 trials)

(5 trials)

(BC1)

(5 trials) (5 trials)
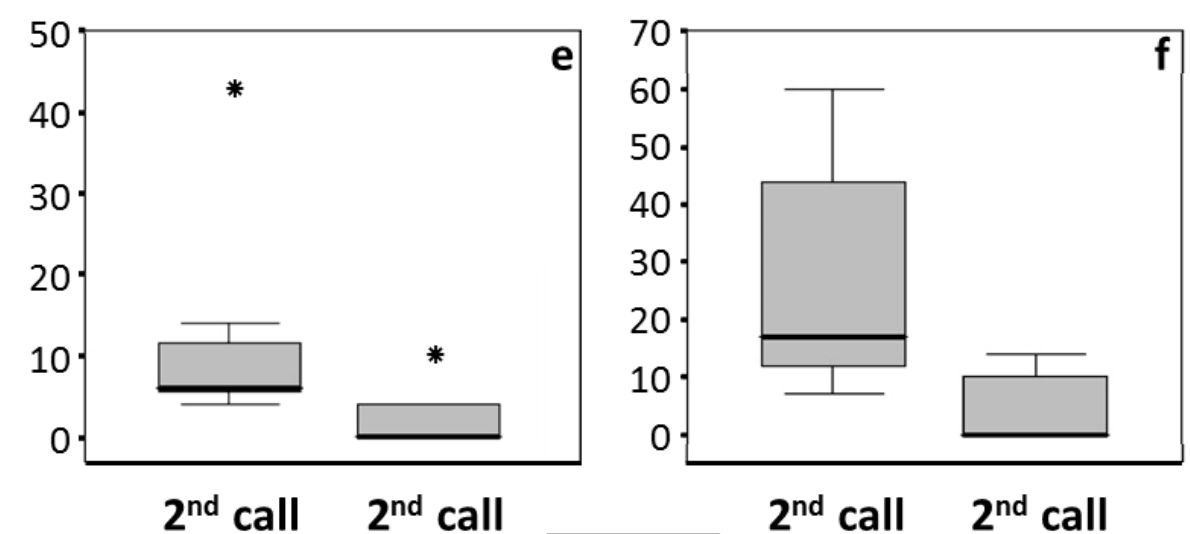

(BT2)

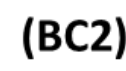

$2^{\text {nd }}$ calls

(BT2)

(8 trials) (5 trials)

Figure 5. Results of Experiment $B$ - unlikely movements. Upper panels a and b: reactions to the two calls (BT1 and BT2) in the test condition with loudspeakes wide apart. Middle panels c and $\mathrm{d}$ : reactions to the two calls (BC1 and $\mathrm{BC} 2$ ) in the control condition with loudspeakes less than 1 $m$ apart. Lower panels e and f: comparison of the second calls in the control condition (BC2) and the test condition (BT2). Graph conventions as for Fig. 3. 